\title{
PAX5 NP_057953.1:p.P80R
}

National Cancer Institute

\section{Source}

National Cancer Institute. PAX5 NP 057953.1:P.P80R. NCI Thesaurus. Code C158142.

A change in the amino acid residue at position 80 in paired box protein Pax-5 where proline has been replaced by arginine. 